\title{
Development of a Test Method Against Hot Alkaline Chemical Splashes
}

\author{
Helena Mäkinen \\ Kalevi Nieminen \\ Susanna Mäki \\ Sirkku Siiskonen
}

\author{
Finnish Institute of Occupational Health, Helsinki, Finland
}

\begin{abstract}
High temperature alkaline chemical liquids have caused injuries and hazardous situations in Finnish pulp manufacturing mills. There are no requirements and/or test method standards concerning protection against high temperature alkaline chemical splashes. This paper describes the test method development process to test and identify materials appropriate for hot liquid chemical hazard protection. In the first phase, the liquid was spilled through a stainless steel funnel and the protection performance was evaluated using a polyvinyl chloride (PVC) film under the test material. After several tentative improvements, a graphite crucible was used for heating and spilling the chemical, and a copper-coated K-type thermometer with 4 independent measuring areas was designed to measure the temperature under the material samples. The thermometer was designed to respond quickly so that peak temperatures could be measured. The main problem was to keep the spilled amount of chemical constant, which unfortunately resulted in significant variability in data.
\end{abstract}

$$
\text { protective clothing hot alkaline liquids recovery boiler testing }
$$

\section{INTRODUCTION}

The primary cooking chemicals for pulp manufacturing are sodium hydroxide and sodium sulphide. In the recovery boiler, black liquor is burned at high temperatures, which results in a very aggressive chemical liquid consisting of sodium carbonate (about 70\%) and sodium sulphide (about $30 \%$ ) with a rapid phase shift from liquid to solid. This hot alkaline solution $\left(800-900{ }^{\circ} \mathrm{C}\right)$ is conveyed through open channels out of the boiler. The hot liquid frequently produces precipitation in the channels, which culminates in process malfunctions. The workers are exposed to splashes of the hot liquid while opening the channels. Therefore, body and face protection is essential [1].

In 2003, a pulp mill contacted the Finnish Institute of Occupational Health subsequent to some serious accidents that had occurred in the mill, despite the mill's adherence to utilising standard type heat protective clothing as defined in Standard No. EN 531:1995 [2]. The workers at the mill used protective garments made of normal flame retardant (FR) fabrics, as well as aluminised fabrics. A general type of heat protective clothing was used because special requirements and test method standards related to hot chemical liquid hazards are currently unavailable, and therefore information of suitable materials is missing. There were no references in the literature for this type of protection problem. Normal textile fibres, such as polypropylene and polyvinyl chloride, have good resistance against alkaline solutions in room temperature, but they will melt in relatively low temperatures, polypropylene in $160-175{ }^{\circ} \mathrm{C}$ and polyvinyl chloride in $200-210{ }^{\circ} \mathrm{C}$ [3]. Semicarbon

This study was funded by the Finnish Work Environment Fund (contract 104375), and by six Finnish recovery boiler mills. They are gratefully acknowledged. We also wish to thank the Finnish Recovery Boiler Committee for their co-operation.

Correspondence and requests for offprints should be sent to Helena Mäkinen, Finnish Institute of Occupational Health, Topeliuksenkatu 41a A, FIN-00250 Helsinki, Finland. E-mail: <helena.makinen@ttl.fi>. 
fibres when blended with other fibres, typically with wool and aramid and with special finish are reported to be suitable for sodium splash protection [4].

EN and ISO standards include methods for testing for protection against chemical splashes or hot solids. In Standard No. EN ISO 6530:2005 [5], $10 \mathrm{ml}$ of chemical in room temperature is applied to the fabric and repellence to liquid is classified from test results. In Standard No. EN 373:1993 [6], a specified amount of metal is heated (e.g., aluminium to $780 \pm 20{ }^{\circ} \mathrm{C}$, iron to $1400 \pm 20^{\circ} \mathrm{C}$ ) and poured onto the fabric. Neither one of these methods is suited to evaluating problems related to hot alkaline liquid splashes.

In the cement industry, workers are exposed to similar hazards as the ones found in pulp mills. These hazards are caused by blockages and accidental releases of hot cement meal at temperatures that may be up to $900{ }^{\circ} \mathrm{C}$ or more. The hot meal can flow like liquid and consequently escape through any unsealed parts of the clinker manufacturing environment [7]. The following personal protective devices are recommended: an airflow helmet with combined front and back apron, a fireman's suit, gloves and sleeves made of $\operatorname{Kevlar} \AA$, and an aluminised one-piece suit.

This paper describes different phases of the test method development. The aim was to develop a test method, which could reliably identify materials and material combinations for protective clothing and other necessary personal protective equipment for recovery boiler workers. This study is a part of a wider investigation in which the protection needs of recovery boiler workers were identified through interviews, questionnaires, as well as measurements in the work places, from which protective clothing with better protection levels was developed.

\section{METHODS}

The starting point for the development of the method was Standard No. EN 373:1993 [6]. This method specifies a testing process for assessing the resistance of protective clothing materials to molten metal splashes. Materials are tested by pouring quantities of molten metal onto the test specimen supported at an angle of $75^{\circ}$ to the horizontal on a pin frame. Damage is assessed by placing an embossed thermoplastic polyvinyl chloride (PVC) sensor film directly behind, and in close contact with the test specimen. Changes to the film after pouring are then recorded. Any adherence of the metal to the test specimen surface is also noted. Depending on the result, the test is repeated using a greater or a smaller mass of metal until the minimum quantity to cause damage to the film is observed. The test apparatus consists of a furnace, a motorised crucible holder, a specimen holder, and a sand tray. Instead of pouring, a predetermined amount of heated liquid chemical is spilled onto the sample utilising a steel funnel with holes.

The pulp manufacturing mill provided the chemical to be tested in solid form. For measurement purposes in the laboratory, the solid chemical was heated in an oven up to temperatures of $800-900{ }^{\circ} \mathrm{C}$ at which point the chemical becomes liquid. The liquid was then spilled through a funnel with holes onto the material sample $(260 \times 100 \mathrm{~mm})$. The measurements were started using stainless steel funnels, but in later stages they were moved to graphite funnels. The ignition, melting and hole formations of the material were evaluated and the effects on the film were assessed. During the first phases, the protective performance was evaluated using a PVC film under the test material; for the latter phases, a copper-coated $\mathrm{K}$-type thermometer was developed and used for assessment purposes.

The measurements were started with a prestudy in the field (phase 1a). Field measurements were made to survey the problem and eliminate the most unsuitable materials. The test method was developed step by step, taking into account any problems arising during the laboratory measurements (phase 1b).

\subsection{Phases 1a and $1 b$}

\subsubsection{Measurements at a recovery boiler mill}

The specimen holder and the size of the specimen followed the specifications indicated by Standard 
No. EN 373:1993 [6]. About $0.1 \mathrm{dm}^{3}$ of hot liquid was taken from the channel and spilled onto to the samples through a stainless steel funnel furnished with 2-mm holes. A PVC sensor film was used for the assessment of burn damage. Figures 1 and 2 illustrate measurements in the field.

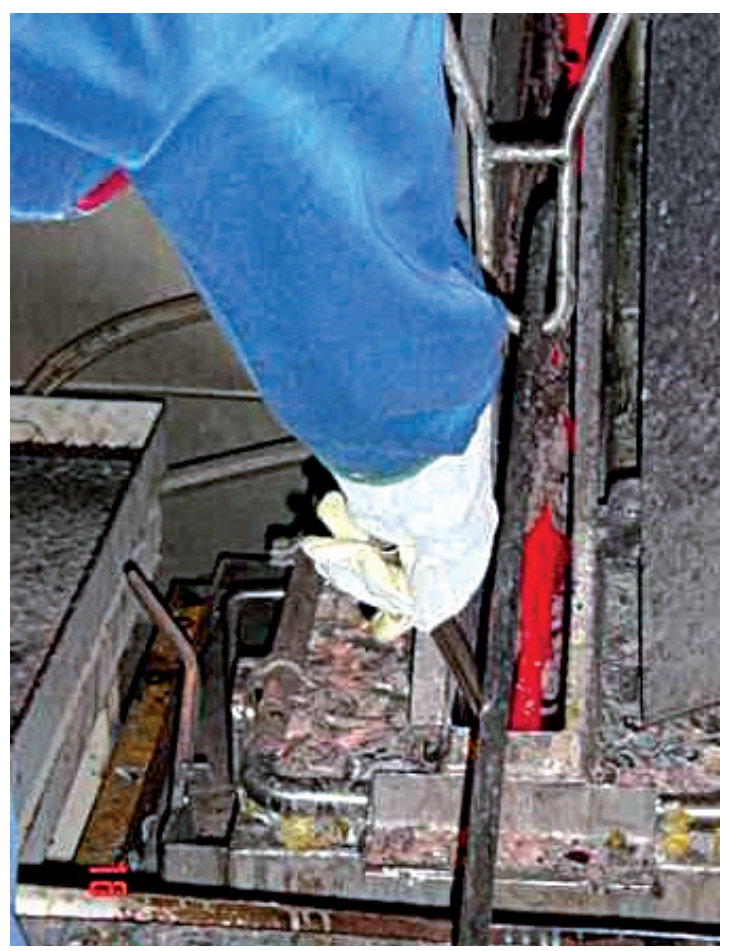

Figure 1. Drawing chemical from channel.

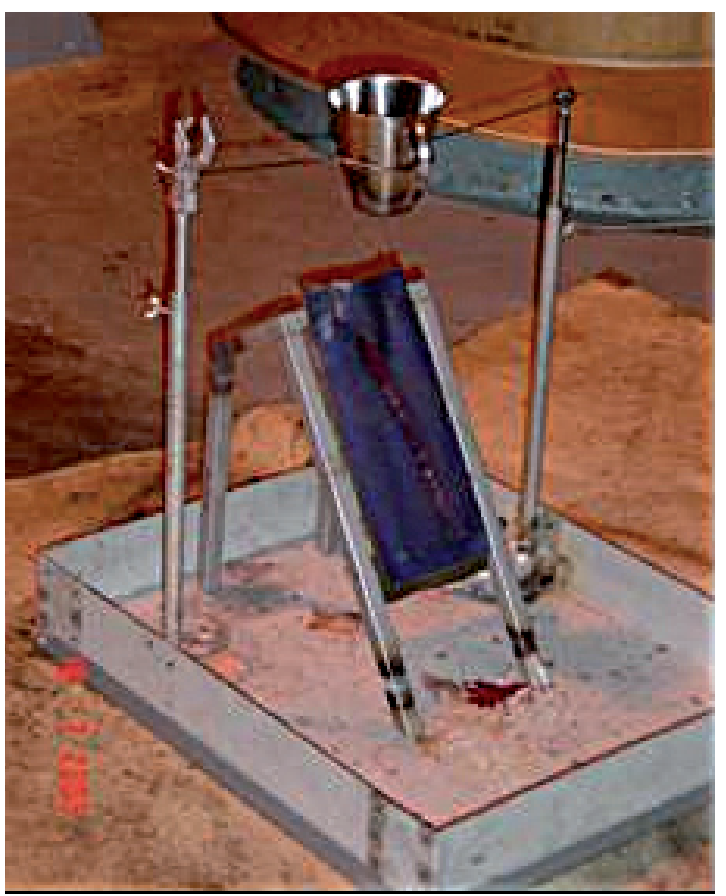

Figure 2. Testing device in the field.

\subsubsection{Measurements in the laboratory}

The measurement procedure was similar to phase 1a as described in section 2.1.1. with the exception that $50 \mathrm{~g}$ of chemical instead of $0.1 \mathrm{dm}^{3}$ of liquid was heated within the furnace (Naberthem L3/12/C6, Naberthem GmbH,

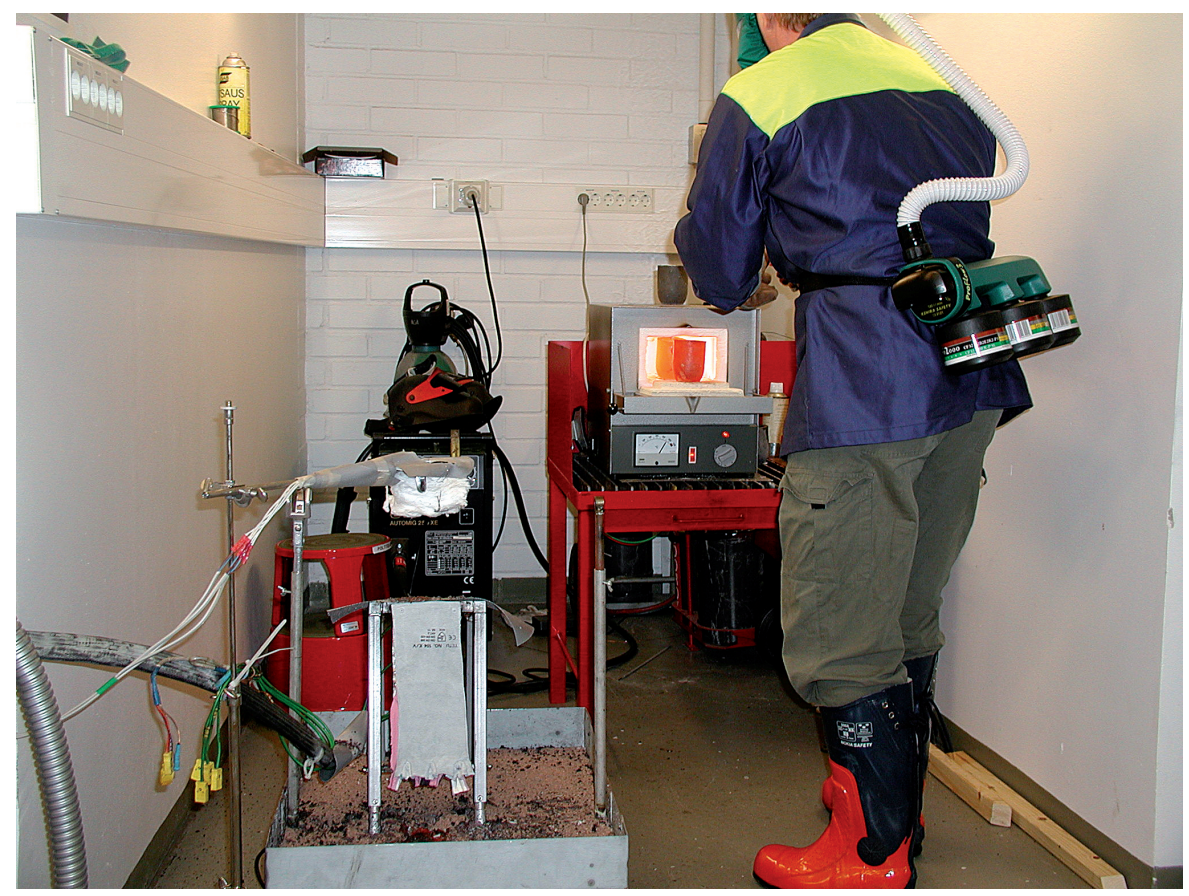

Figure 3. Testing in the laboratory. 
Germany) in a crucible until it was in liquid form. The temperature of the liquid was the furnace temperature $\left(790-830{ }^{\circ} \mathrm{C}\right.$ ), because this high temperature alkaline liquid damaged the sensor, and an actual temperature measurement was unattainable. A hot air fan was used to prevent rapid cooling of the funnel. The amount of the spilled chemical was measured using a weighing system, in which the whole spilling system was set on a Sartorius IB 34EDE balance (Sartorius $\mathrm{GmbH}$, Germany). The balance was tare weighed before every spilling (Figure 3).

\subsection{Phases $2 a$ and $b$}

\subsubsection{Phase $2 a$}

The measurement procedure was identical to phase $1 \mathrm{~b}$ using a stainless steel funnel except that a coppercoated K-type thermometer was used to measure the temperature under the sample instead of a PVC film. The temperature measuring system consisted of four separate thermometers (Figure 4). The width of one sensor plate was $100 \mathrm{~mm}$, the height $40 \mathrm{~mm}$, and the total height $220 \mathrm{~mm}$. The thickness of copper was $0.5 \mathrm{~mm}$. The temperature of the chemical

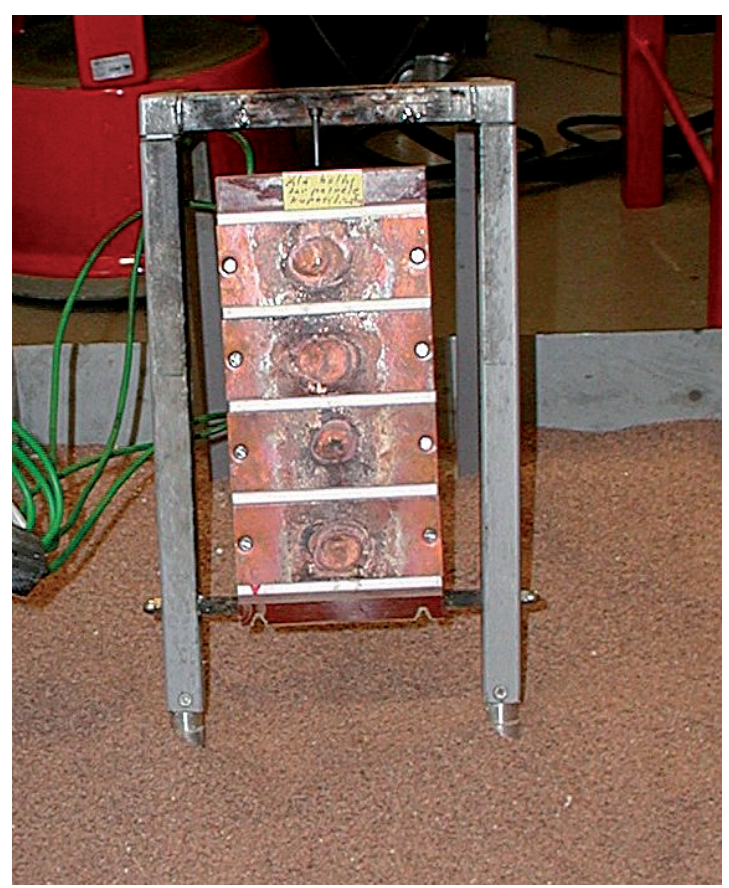

Figure 4. Copper-coated K-type thermometer for temperature measurements. was measured with a K-type temperature probe T204-021-585 (SAB Bröckskes, Germany) with a measurement range of $-200-1370{ }^{\circ} \mathrm{C}$ and accuracy of $\pm 1.1-2.2{ }^{\circ} \mathrm{C}$. The measurement equipment used was an Agilent 34970A (Agilent Technologies, Inc. USA) data-logger with an accuracy of $\pm 1.2{ }^{\circ} \mathrm{C}$. Figure 5 shows a display of the temperature measurement.

\subsubsection{Phase $2 b$}

The measurement procedure was identical to phase $2 \mathrm{a}$, except that it used heating patrons (about $700{ }^{\circ} \mathrm{C}$ ) evenly located around the funnel to keep the chemical in liquid form.

\subsection{Phase 3}

The measurement procedure was similar to phase $2 \mathrm{~b}$ except that the liquid was spilled through a graphite funnel with 4-mm holes instead of a stainless steel funnel. An induction oven was used to prevent the cooling of the funnel. The measurement system and the funnel were insulated using Mica electrical insulation plates to prevent radiation heat from escaping into the environment.

\subsection{Materials}

The materials were conditioned at $20 \pm 2{ }^{\circ} \mathrm{C}$ and $65 \pm 5 \% \mathrm{RH}$ before testing. In each phase, combinations of traditional FR fabrics, coated materials, and uncoated material combinations from the market were measured. The materials were tested without prewashing. In Table 1, the materials tested during phase 1 are shown. During phases 2 and 3 the measurements were continued with various materials and material combinations from the market. For further study 10 materials were selected (Table 2). Measurements were taken on 14 combinations of single-, two-, and three-layer materials. Each measurement was performed three times. 


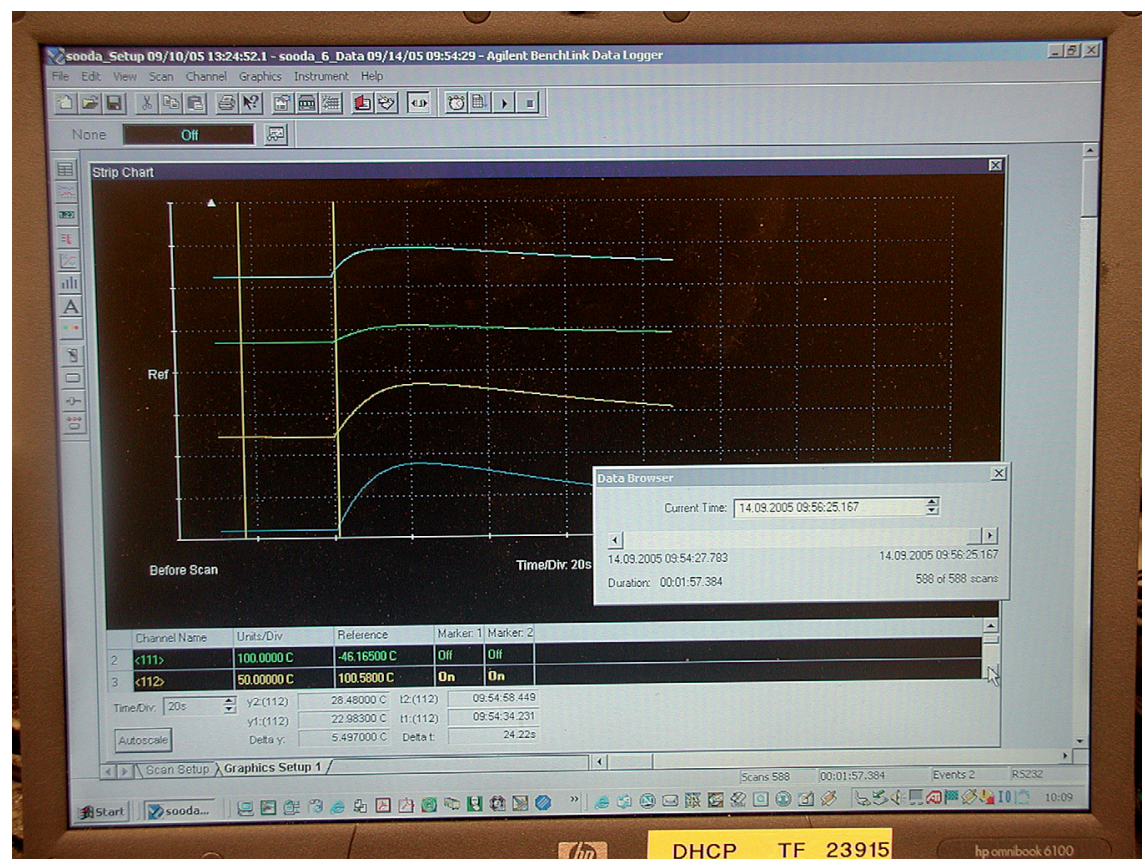

Figure 5. Display of the temperature measurements system.

TABLE 1. Tested Materials and Their Behaviour in Test Phase 1, When a PVC Film Was Used as an Assessment Method

\begin{tabular}{|c|c|c|c|}
\hline No. & Material & Ignition, Burning & Behaviour of Material and PVC Film \\
\hline 1 & $70 / 30 \%$ FR CO/PES & no & charred through PVC film: melted through \\
\hline 2 & $100 \%$ FR CO, thin & no & charred through PVC film: melted through \\
\hline 3 & CO $100 \%$ FR, thick & no, smoked & charred, no hole PVC film: surface pattern melted \\
\hline 4 & 75/25\% FR CO/Kevlar® & no & charred through PVC film: melted through \\
\hline 5 & 55/45\% PPAN/FR CO & no & burned through PVC film: melted through \\
\hline 6 & $50 / 50 \%$ FR CO/PES & yes & $\begin{array}{c}\text { ignited and continued to burn PVC film: melted } \\
\text { through }\end{array}$ \\
\hline 7 & split leather & no & $\begin{array}{l}\text { leather hardened PVC film: surface pattern melted, } \\
\text { no hole }\end{array}$ \\
\hline 8 & 2 layers of $70 / 30 \%$ FR CO/PES & yes & $\begin{array}{l}\text { outer layer charred through, under layer partly PVC } \\
\text { film: surface pattern melted }\end{array}$ \\
\hline 9 & $\begin{array}{l}\text { 75/25\% FR CO/Kevlar® + } 100 \% \\
\text { FR CO }\end{array}$ & no & smoked, charred PVC film: melted through \\
\hline 10 & $\begin{array}{c}100 \% \text { FR CO + 75/25\% FR CO/ } \\
\text { Kevlar@ }\end{array}$ & no & $\begin{array}{l}\text { outer layer charred though, under layer darkened } \\
\text { PVC film: surface pattern melted, no hole }\end{array}$ \\
\hline 11 & $\begin{array}{c}\text { on both sides silicon-coated fabric } \\
\text { + FR cotton fabric }\end{array}$ & no & $\begin{array}{l}\text { outer fabric: small dark spots FR cotton fabric: small } \\
\text { charred spots PVC film: small melt spots }\end{array}$ \\
\hline 12 & $\begin{array}{c}\text { silicon-coated Kevlar@ fabric + FR } \\
\text { cotton fabric }\end{array}$ & no & $\begin{array}{l}\text { outer fabric: some droplets fastened FR cotton } \\
\text { fabric: PVC film }\end{array}$ \\
\hline 13 & aluminium-coated fabric & no, smoked & material: burned through PVC film: melted through \\
\hline 14 & glass fibre fabric & no & material: colour changes PVC film: melted through \\
\hline 15 & Nomex®/GORE-TEX® fabric & no & $\begin{array}{l}\text { fastened on the surface, shrank, no hole PVC film: } \\
\text { softened, surface pattern disappeared }\end{array}$ \\
\hline 16 & $\begin{array}{l}\text { 3-layer PBI/Kevlar® with GORE- } \\
\text { TEX® Firelocker and Nomex®- } \\
\text { vadd with Nomex®-fabric }\end{array}$ & no & $\begin{array}{l}\text { fastened on the outer fabric, Firelocker shrank, no } \\
\text { holes PVC film: gloss, surface pattern unchanged }\end{array}$ \\
\hline 17 & $\begin{array}{l}\text { 3-layer FR fabric with Sympatex® } \\
\text { moisture barrier + FR cotton fabric }\end{array}$ & smoked & $\begin{array}{l}\text { outer 3-layer sample: charred through FR cotton: } \\
\text { charred PVC film: melted and fastened on the FR } \\
\text { fabric }\end{array}$ \\
\hline
\end{tabular}

Notes. FR-flame retardant, CO—cotton, PES—polyester, PVC—polyvinyl chloride, PPAN-pyrolised polyacrylonitrile, $\mathrm{PBI}$-polybenzimidazole. 
TABLE 2. Materials in Parallel Measurements

\begin{tabular}{|c|c|c|c|}
\hline No. & Material Specification & Construction & Weight $\left(\mathrm{g} / \mathrm{m}^{2}\right)$ \\
\hline 1 & $55 \%$ Protex (modacrylic), 45\% CO & knitted fabric & 205 \\
\hline 2 & $55 \%$ Protex, $45 \%$ CO & piqué knit & 240 \\
\hline 3 & $50 \%$ CV, $30 \%$ WO, 17\% PES, 3\% R-stat & satin weave & 345 \\
\hline 4 & $55 \%$ Protex, $45 \%$ CO & satin weave & $270 / 275$ \\
\hline 5 & $100 \%$ Kevlar@ & woven twill 2/1 & 380 \\
\hline 6 & Alupigmented silicone-coated 30\% Kevlar®, 70\% Panox® & woven twill 2/1 & 340 \\
\hline 7 & $50 \%$ Nomex®, 50\% Kevlar® & woven twill 2/1 & 480 \\
\hline $8 a$ & $\begin{array}{c}45 \% \text { WO, } 24 \% \text { CO, } 18 \% \text { PPAN-FR, } 13 \% \text { PES (pool:100\% } \\
\text { WO), }\end{array}$ & pool fabric & 450 \\
\hline $8 b$ & $\begin{array}{c}\text { 45\% WO, } 24 \% \text { CO, } 18 \% \text { PPAN-FR, } 13 \% \text { PES (pool:100\% } \\
\text { WO), inside up }\end{array}$ & pool fabric & 450 \\
\hline 9 & $50 \%$ FR viscose, $40 \%$ WO, $10 \%$ PA & woven $2 / 1$ twill & 340 \\
\hline 10 & $70 \%$ CO, 30\% PES & woven twill & 320 \\
\hline
\end{tabular}

Notes. CO-cotton, CV-viscose, WO-wool, PES-polyester, R-stat-antistatic fibre, PPAN-pyrolised polyacrylonitrile, FR-flame retardant, PA-polyamide.

\section{RESULTS}

\subsection{Phase 1}

During the field measurements, there were difficulties with obtaining comparable amounts of liquid from the recovery boiler funnel for spilling purposes. The liquid began to cool and rapidly solidify, and subsequently stuck to the funnel walls. Through the measurements of 17 fabrics and fabric combinations (Table 1), initial impressions of the aggressiveness of this chemical were formulated. Typical FR fabrics provided insufficient protection. Some fabrics ignited and continued to burn despite meeting the Standard No. EN 531:1995 [2] requirement for limited flame spread. In most cases, the PVC film melted through. Similarly, layered aramid fabrics with moisture barriers for fire fighters' use appeared unsuitable given that chemical drops tended to stick to the fabric's surface and the PVC film surface patterns tended to melt. Aluminium-coated fabrics burned through and the PVC film under the fabric melted through.

In the laboratory measurements during phase $1 \mathrm{~b}$, the temperature of the furnace when the liquid was taken out was $800-830{ }^{\circ} \mathrm{C}$ and the mass of the spilled liquid varied between 14.4 and $66.0 \mathrm{~g}$. It was difficult to keep the funnel holes unclogged. Moreover, because a fan was used to prevent the funnel from cooling, the hot liquid tended to drip onto the backside of the sample. Siliconcoated fabrics with FR cotton fabrics (Table 1, No. 11 and 12), 3-layer polybenzimidazole (PBI)/ Kevlar ${ }^{\circledR}$ with GORE-TEX® Firelocker and Nomex®-vadd with Nomex®-fabric (Table 1, No. 16) and split leather (Table 1, No. 7) provided the best protection. For these fabrics, only a few melted spots on the PVC skin were found after the chemical was spilled. Satisfactory repeatability of test conditions was not achieved due to the high scatter of poured chemicals mass.

\subsection{Phase 2}

The new additional warming system, which included heating patrons, kept the chemical in liquid form, but the steel funnel was unable to withstand the increased temperature and aggressive alkaline chemical and subsequently began to burn.

\subsection{Phase 3}

The ceramic crucibles functioned well for several consecutive spills, although the holes for spilling tended to increase in diameter with use. Therefore, any given funnel could only be used for eight spills.

The mean temperature of the furnace when the chemical was taken out was $909{ }^{\circ} \mathrm{C}(S D$ 21.3). The mean amount of spilled chemical was $43.2 \mathrm{~g}(S D$ 5.9). Figure 6 shows the mean furnace 

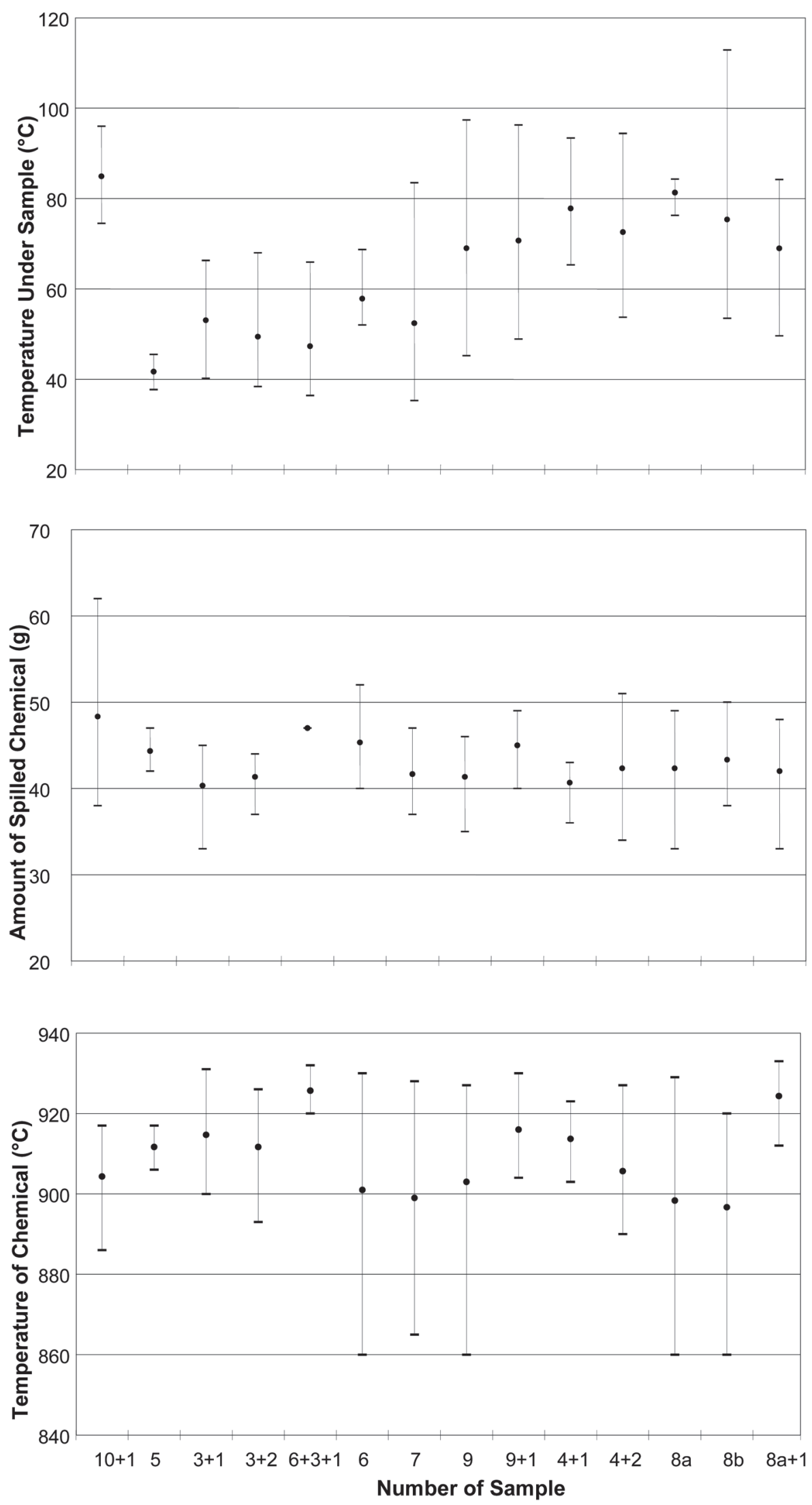

Figure 6. Variation of temperature, amount of chemical, and temperature under the sample in repeated measurements of phase 3 tests. 
(a)

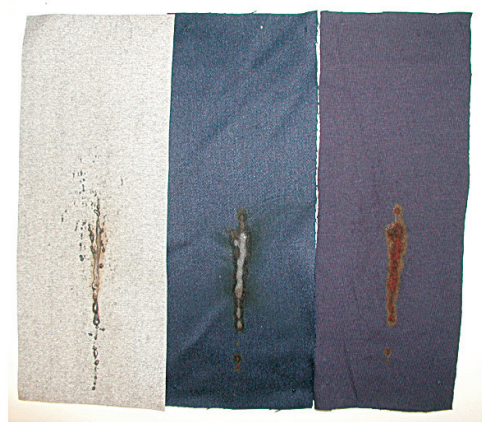

(b)

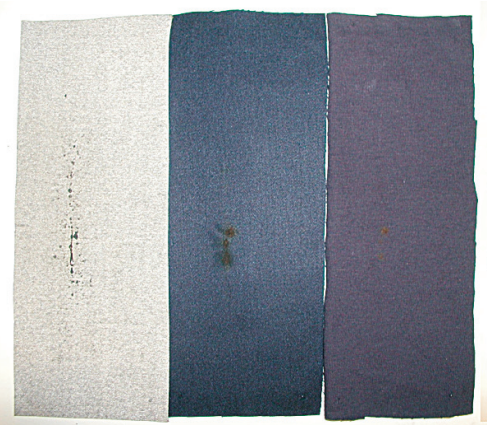

(c)

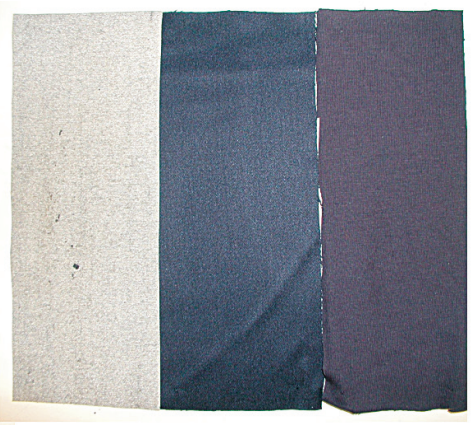

Figure 7. Behaviour of combination $6+3+1$ in three separate tests.

temperature and variation of the chemical, mean amount and variation of the spilled chemical, and the highest measured temperatures and variation under the samples for the materials and material combinations for which three repeated measurements were made. For the material combination of alupigmented silicone-coated $30 / 70 \% \quad \operatorname{Kevlar} \AA / P a n o x \circledR, \quad$ Teflon ${ }^{\circledR}$-finished 50/30/17/3\% FR viscose (CV)/wool (WO)/ polyester (PES)/ antistatic fibre (R-stat) fabric and $55 / 45 \%$ Protex/cotton (CO) knitted fabric (Table 2, material $6+3+1$ ), the temperature of the chemical and the amount of the spilled chemical was successfully kept constant. However, a clearly lower variation for the temperature under the sample was not observed; the difference between the highest and lowest temperature was $29.5^{\circ} \mathrm{C}$. Figure 7 shows the results of different layers of combination $6+3+1$ in three separate measurements. This combination was finally selected for prototype garment fabrics, as this provided the best compromise of performance against wear ability [8].

The lowest maximum temperature increase $\left(37.7-45.5^{\circ} \mathrm{C}\right.$ ) was measured for $100 \% \operatorname{Kevlar}{ }^{\circledR}$ fabric, but this fabric is unsuitable for normal clothing purposes. Also, a low temperature increase $\left(40.2-66.3^{\circ} \mathrm{C}\right)$ was measured for Teflon $\AA$-finished 50/30/17/3\% FR viscose (CV)/ WO/PES/R-stat fabric with 55/45\% Protex/CO knitted fabric (Table 2, No. 3 and 2). Figure 8 presents the temperatures of four sensors and pictures of fabric layers of this combination.

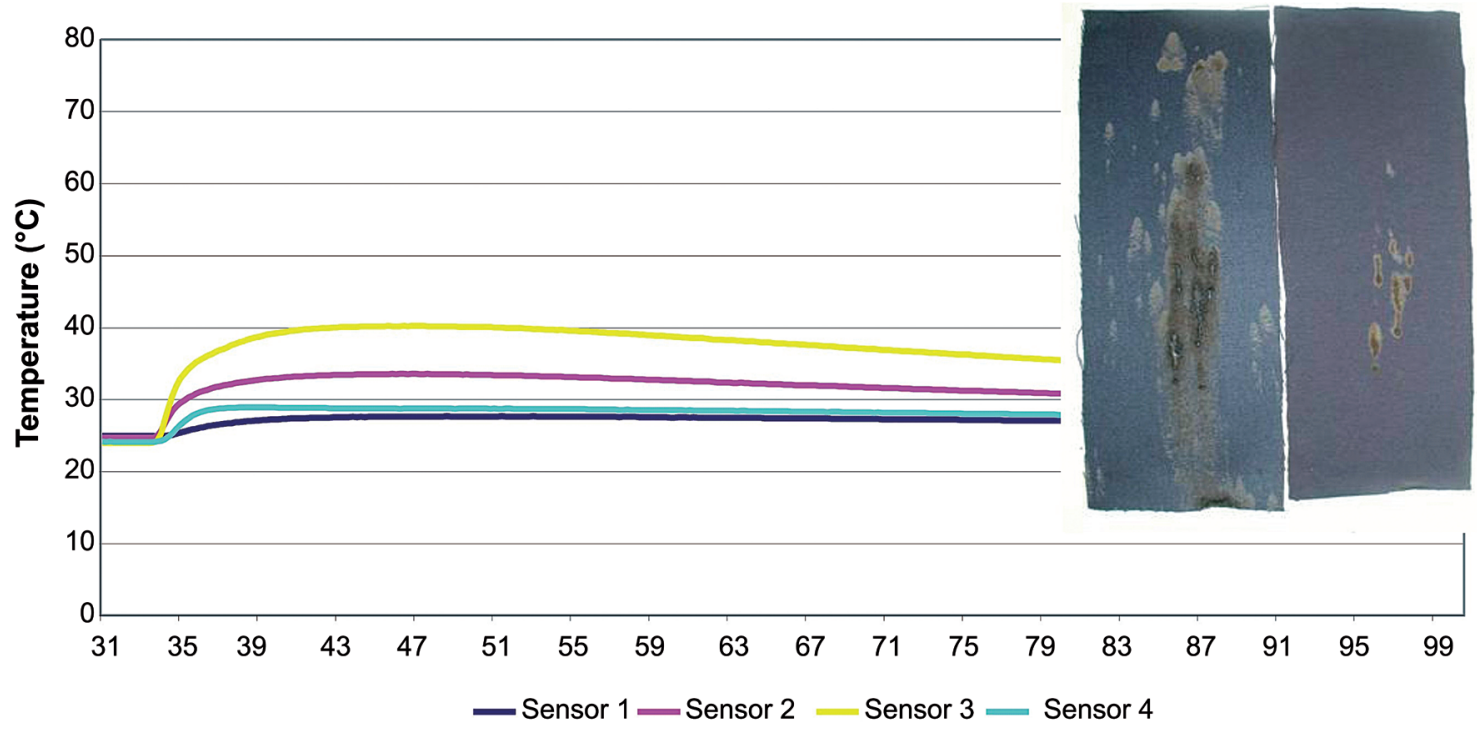

Figure 8. Temperature increase for sample $6+1$; an example of a low temperature increase. 


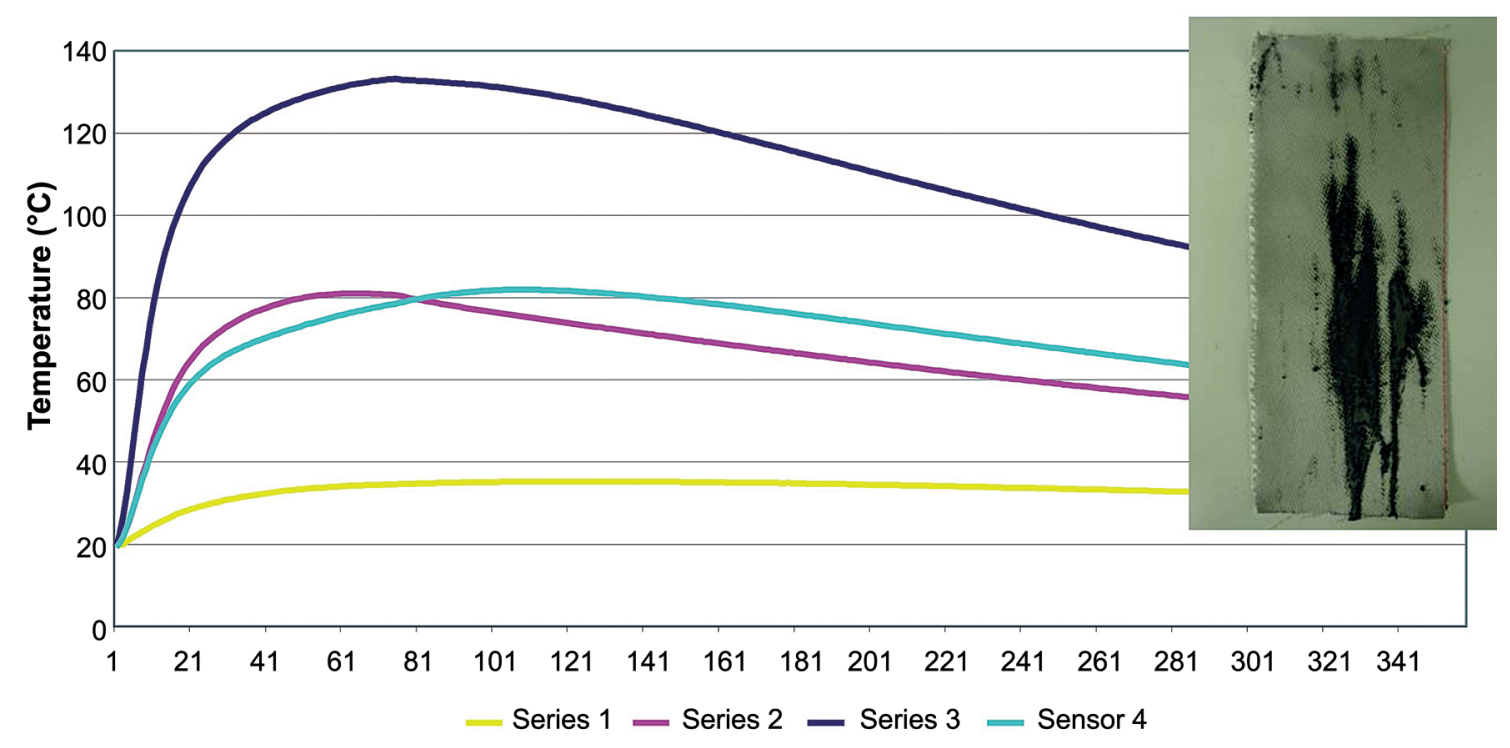

Figure 9. Temperature increase for sample 16; an example of a rapid temperature increase.

The time for the temperature increases of 12 and $24^{\circ} \mathrm{C}$ under the sample was very short for most of the measured fabrics. The chemical did not run off, but penetrated most materials, causing a rapid and high temperature increase. Figure 9 shows the behaviour of the material and how the temperature increased for silicon-coated glass fibre fabric up to a peak temperature of $133^{\circ} \mathrm{C}$ in one sensor area plate, and up to $80^{\circ} \mathrm{C}$ in two other measurement areas.

\section{DISCUSSION AND CONCLUSION}

The development process began with bringing the test device to the work site, and positioning it near the recovery boiler. The test results provided estimates on protective levels for some typical fire retardant fabrics used in paper mills. The tests were continued in a laboratory environment. Despite modifications during the development process, the quantity of the spilled chemical and the temperatures under the test samples remained variable. This may have been due to a possible change in the chemical formula, such as one occurring through the solid chemical received from the pulp mill being exposed to air. During the field tests, the chemical was obtained directly from the recovery boiler process, but other parameters like the mass of the high temperature liquid was difficult to control. Other possible explanations for the variations under the laboratory samples include the chemical sticking to the outer surfaces of the material, differences in spilling procedure, and the rapid phase change of the chemical (i.e., from liquid to solid) despite the additional heating system. The total inaccuracy of the testing system is influenced by the accuracy of the temperature measurement (which was calculated for the worst case of $\pm 5.7{ }^{\circ} \mathrm{C}$ ), the variation of the mass of the chemical, the variation of the temperature of the chemical, and how the chemical flows on the sample during the test. Despite the inaccuracies of the testing system, the method can be used to find materials and material combinations for added protection of recovery boiler workers and other industries' workers facing similar occupational hazards.

According to safety regulations, engineering controls, process change, equipment change, administrative controls, material substitution and revised work practices are the primary methods in the protection strategy before the use of personal protective equipment. In this case, when handling very aggressive hot chemicals, these controls are highly important: if the level of hazard is reduced, a lower level protection may be acceptable, and more comfortable personal protection can be used.

The handling of the high temperature alkaline liquid during testing is not safe without planned 
safety control measures. The hot chemical produces hazardous fumes, thus a powered respiratory protection with a face shield is needed, as well as leather protective gloves, fire retardant protective clothing and safety footwear against hot liquid splashes. Also an emergency shower and a first-aid fire-extinguishing device are needed.

\section{REFERENCES}

1. Mäkinen $\mathrm{H}$, Karkkula $\mathrm{S}$, Mäki $\mathrm{S}$, Koskinen H. Protecting recovery boiler workers against hot chemical splashes. In: Podgórski D, Majchrzycka K, Pleban D, editors. Proceedings of the International Conference. Research and standardization in the field of development and use of personal protective equipment. Warszawa, Poland: Central Institute for Labour Protection - National Research Institute; 2005. p. 329-33.

2. European Committee for Standardization (CEN). Protective clothing for industrial workers exposed to heat (Standard No. EN 531:1995). Brussels, Belgium: CEN; 1995.

3. Haudek HW, Viti E. Textilfasern. Perchtoldsdorf bei Wien, Austria: Johann L. Bondi \& Sohn; 1980.
4. Horrocks AR. Thermal (heat and fire) protection. In: Scott RA, editor. Textiles for protection. Boca Raton, FL, USA: CRC Press; 2006.

5. International Organization for Standardization (ISO). Protective clothing. Protection against liquid chemicals. Test method for resistance of materials to penetration by liquids (Standard No. ISO 6530:2005). Geneva, Switzerland: ISO; 2005.

6. European Committee for Standardization (CEN). Protective clothing. Assessment of resistance of materials to molten metal splash (Standard No. EN 373:1993). Brussels, Belgium: CEN; 1993.

7. British Cement Association (BCA). Guidance to prevent hot meal burns. 2nd ed. Camberley, Surrey, UK: BCA.

8. Mäki S, Koskinen H, Mäkinen H. Protective clothing and other personal protective equipment (PPE) against high temperature liquid splashes for recovery boiler workers [abstract]. In: 3rd European Conference on Protective Clothing (ECPC) and NOKOBETEF 8. Protective clothingtowards balanced protection. Warszawa, Poland: Central Institute for Labour Protection - National Research Institute; 2006. p. 102. 